\title{
Кузнецова И.В.
}

Кузнецова Ирина Вадимовна - Ивановский государственный химико-технологический университет, старший преподаватель кафедры физической культуры.

E-mail: kuznetsova_iv@isuct.ru.

\section{РЕАЛИЗАЦИЯ ВАРИАТИВНОГО КОМПОНЕНТА ДИСЦИПЛИНЫ «ФИЗИЧЕСКАЯ КУЛЬТУРА» НА ОСНОВЕ ЦИФРОВЫХ ФИТНЕС-ТЕХНОЛОГИЙ}

\begin{abstract}
В статье рассматриваются вопросы организации занятий физической культуры в студенческой среде, научно обосновывается возможность использования актуальных ичфровых фитнес-технологий в процессе формирования общекультурных компетенций в контексте современного образования. Дается оценка эффективности влияния оздоровительной аэробики на уровень физической подготовленности и мотивации студентов. Приводятся сравнительные характеристики практических занятий $c$ преподавателем в зале и дистанционных занятий с применением циифровых фитнес-технологий. Отмечен вариативный компонент практических занятий по физической культуре в основных медицинских группах в вузах нефизкультурного профиля.
\end{abstract}

Ключевые слова: физическая культура, вариативный компонент, цифровые фитнес-технологий, студенческая молодежь.

\section{Kuznetsova I.V.}

Kuznetsova I.V. - Senior Lecturer, Ivanovo State University of Chemistry and Technology. E-mail: kuznetsova_iv@isuct.ru.

\section{FORMS OF COMBINING TRADITIONAL AND INNOVATIVE METHODS IN TEACHING PHILOSOPHICAL DISCIPLINES}

The article discusses the issues of organizing physical education classes with students, the possibility of using relevant digital fitness technologies in the process of forming general cultural skills in the context of modern education is scientifically supported. The effectiveness of the influence of health related aerobics on the level of physical fitness and motivation of students is estimated. Comparative characteristics of practical classes with a teacher in the gym and distance classes using digital fitness technologies are given. The variable component of practical physical culture classes in the main medical groups in universities of non-physical education profile is noted.

Key words: physical culture, variable component, digital fitness technologies, student youth. 


\section{Введение.}

Динамические изменения, происходящие в настоящее время во всех сферах общества, а также переход на цифровое обучение, не могли не затронуть и систему высшего образования в области физического воспитания. В настоящее время проблема освоения ценностей физической культуры определяется как социально-значимая задача. Для решения на практике проблемы приобщения студенческой молодежи к физкультурной деятельности необходим поиск вариативных компонентов организации занятий, включая использование цифровых фитнес-технологий.

Цель исследования - научно обосновать возможность использования современных цифровых фитнес-технологий в процесс формирования общекультурных компетенций в контексте современного образования.

\section{Методика и организация исследования.}

В экспериментальном исследовании приняли участие 90 студентов 1-3 курсов Ивановского государственного химико-технологического университета. Возраст участников 17-20 лет. Было сформировано 3 группы. В качестве контрольной группы (КГ) взяты результаты потока студентов, обучающихся физической культуре по традиционной программе. Две экспериментальные группы состояли из студентов, избравших дисциплину «Оздоровительная фитнес-технология». Занятия состояли в основном из танцевальных и силовых компонентов упражнений. Первая экспериментальная группа (ЭГ-1) занималась в спортивном зале под наблюдением преподавателя. Вторая экспериментальная группа (ЭГ-2) занималась дистанционно с использованием видеоуроков. Уровень освоения компетенций по дисциплине рассматривался в соответствии с фондом оценочных средства (ФОС) рабочей программы, где дисциплины представлены контрольно-измерительные материалы и методы их использования для оценивания достижений и результатов студента по изучению предмета.

Данные физического развития сравнивались с исходными данными начала учебного года, а данные физической подготовленности подверглись математическому анализу. Кроме того, для выявления интересов студенческой молодежи к формам физкультурной деятельности был проведен социально-педагогический мониторинг, который включал:

- исходные и конечные показатели физической подготовленности у участников эксперимента;

- показатели посещаемости студентами занятий в течение эксперимента.

Для анализа были использованы такие нормативы, как:

- сгибание и разгибание рук в упоре лежа;

- подъем туловища за 1 мин.;

- бег на 100 м;

- гибкость;

- прыжок в длину.

Если в начале эксперимента исходные показатели физической подготовленности студентов были приблизительно на одном уровне, то в конце года был отмечен прирост показателей (Табл.1). 
Таблица 1

Прирост анализируемых показателей (\%) на конец года по сравнению с началом эксперимента

\begin{tabular}{|l|c|c|c|}
\hline \multicolumn{1}{|c|}{ Нормативы } & ЭГ-1 & ЭГ-2 & КГ \\
\hline Сгибание и разгибание рук в упоре лежа & 46 & 43 & 11 \\
\hline Подъем туловища за 1 мин. & 46 & 44 & 15 \\
\hline Бег на 100 м & 4,7 & 0,0 & 2,8 \\
\hline Гибкость & 38 & 36 & 12 \\
\hline Прыжок в длину & 11 & 5 & 9 \\
\hline
\end{tabular}

Анализируя полученные данные мы видим, что наибольшим приростом показателей отличается ЭГ-1, где практические показатели проходили в зале, под наблюдением преподавателя. Большой интерес у студентов вызвали занятия с использованием цифровых фитнес-технологий (ЭГ-2), но результат оказался немного ниже, чем в ЭГ-1. Небольшой прирост показала и КГ. Это указывает на отсутствие мотивации к занятиям.

Следует отметить, что посещаемость занятий во всех экспериментальных группах значительно выше, чем в КГ. Если в начале эксперимента процент посещаемости составлял 75\%, но к концу эксперимента в ЭГ-1 посещаемость повысилась до 96\%, в ЭГ-2 - до 98\%, что говорит о несомненном интересе к выбранному виду занятий. В КГ процент посещаемости изменился незначительно и составил $77 \%$ (Рис. 1 ).

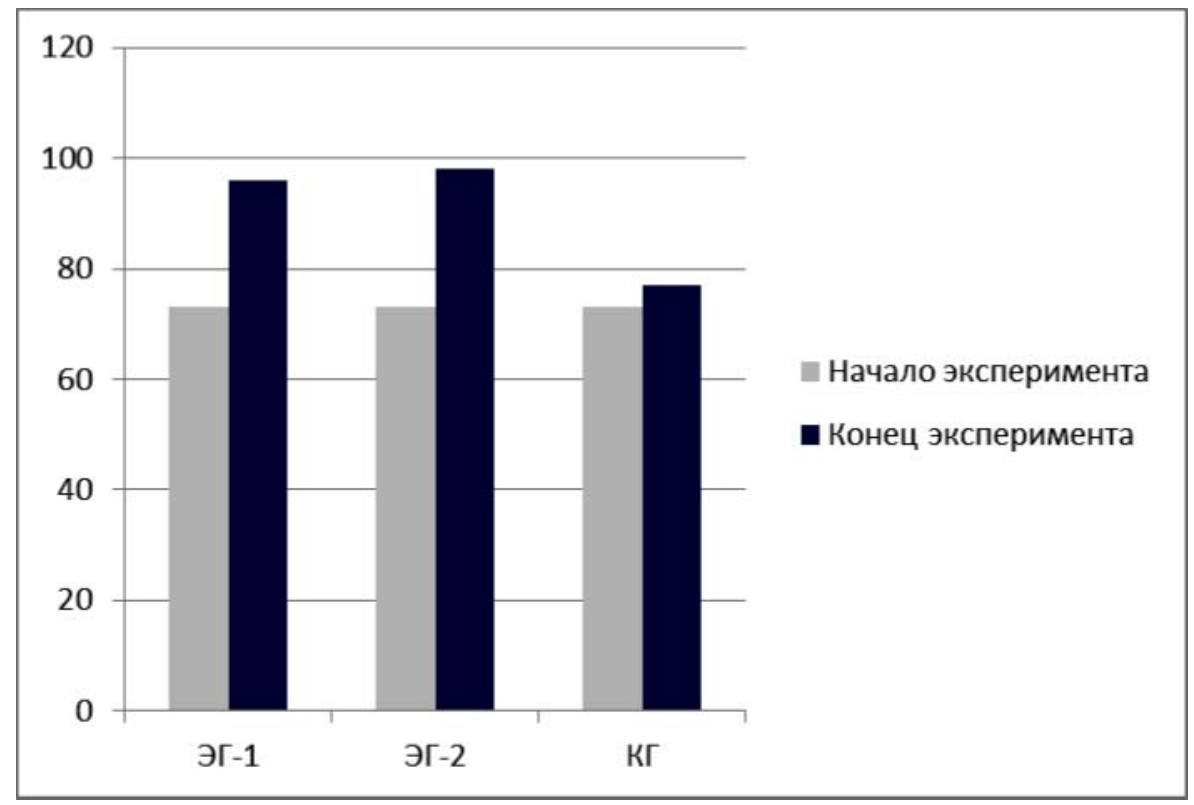

Рис. 1. Процентное соотношение посещаемости занятий в начале и конце эксперимента 
Следует также отметить, что после окончания эксперимента 83\% студентов из ЭГ-2 (занимающихся дистанционно) отметили, что предпочли бы занятия в спортивном зале. В данном случае перевес в сторону парадигмы «человек-человек».

\section{Результаты исследования и их обсуждение.}

Полученные данные позволяют сделать вывод, что предлагаемый вариативный компонент позволяет отметить в ЭГ-1 и ЭГ-2 тенденцию к улучшению физического развития. Под влиянием занятий с использованием оздоровительных фитнестехнологий существенно расширились показатели физической подготовленности студентов к концу учебного года. К положительным результатам исследования следует отнести и приобретение разнообразных двигательных навыков, увеличение силы мышц, подвижности суставов, улучшение гибкости, повышение функциональных возможностей и работоспособности организма. Наряду с этим, танцевальный характер упражнений способствует повышению выразительности и культуры в целом. Также необходимо отметить, что посещаемость занятий в ЭГ-1 и ЭГ-2 была выше, чем в КГ. Использование музыки повышает интерес к занятиям, а также увеличивает нагрузку, не вызывая утомления, органическая связь движений и музыки содействует эстетическому воспитанию студентов.

\section{Выводы.}

Результаты исследования позволяют рассматривать занятия с использованием оздоровительных фитнес-технологий как вариативный компонент практических занятий по физической культуре, так и в случае необходимости, на дистанционных занятиях в основных медицинских группах в вузах не физкультурного профиля.

\section{СПИСОК ЛИТЕРАТУРЫ}

1. Карасева Е.Н. Физическое воспитание студентов высших учебных заведений на основе использования оздоровительных гимнастических систем: дисс... канд. пед. наук. М., 2012. $191 \mathrm{c}$.

2. Кузнецова И.В. Аэробика как фактор повышения мотивации к занятиям физической культурой // Сборник материалов научно-методической конференции. Иваново: ИГХТУ. 2005. С.129.

3. Кузнецова И.В. Влияние занятий оздоровительной аэробикой на качество профессиональной подготовки студентов // Сборник материалов Международной научно-технической конференции. Часть І. Иваново. 2006. С. 281 - 283.

4. Кузнецова И.В. Повышение качества подготовки выпускников технического вуза путем приобщения к занятиям физкультурой (на примре оздоровительной аэробики) // Сборник материалов Региональной научно-методической конференции. Иваново: ИГХТУ. 2002. С. 32.

5. Кузнецова И.В. Реализация вариативного компонента дисциплины «Физическая культура» // Сборник материалов научно-методической конференциию Иваново: ИГХТУ. 2016. С. 91.

6. Кузнецова И.В. Роль и значение оздоровительной аэробики в физкультурном образовании студентов вузов // Сборник материалов Международной научнопрактической конференции. Шуя: ШГПУ. 2002. С. 85-86.

7. Осыченко М.В. Фитнес как главный компонент формирования здорового образа жизни студенческой молодежи // Вестник АПК Ставрополья. 2012. №4(8) С. 12-14. 


\section{REFERENCES (TRANSLITERATED)}

1. Karaseva Ye.N. Fizicheskoye vospitaniye studentov vysshikh uchebnykh zavedeniy na osnove ispol'zovaniya ozdorovitel'nykh gimnasticheskikh sistem: diss... kand. ped. nauk. M., 2012. $191 \mathrm{~s}$.

2. Kuznetsova I.V. Aerobika kak faktor povysheniya motivatsii $\mathrm{k}$ zanyatiyam fizicheskoy kul'turoy // Sbornik materialov nauchno-metodicheskoy konferentsii. Ivanovo: IGKHTU. 2005. S. 129.

3. Kuznetsova I.V. Vliyaniye zanyatiy ozdorovitel'noy aerobikoy na kachestvo professional'noy podgotovki studentov // Sbornik materialov Mezhdunarodnoy nauchno-tekhnicheskoy konferentsii. Chast' I. Ivanovo. 2006. S. $281-283$.

4. Kuznetsova I.V. Povysheniye kachestva podgotovki vypusknikov tekhnicheskogo vuza putem priobshcheniya k zanyatiyam fizkul'turoy (na primre ozdorovitel'noy aerobiki) // Sbornik materialov Regional'noy nauchno-metodicheskoy konferentsii. Ivanovo: IGKHTU. 2002. S. 32.

5. Kuznetsova I.V. Realizatsiya variativnogo komponenta distsipliny «Fizicheskaya kul'tura» // Sbornik materialov nauchno-metodicheskoy konferentsiiyu Ivanovo: IGKHTU. 2016. S. 91.

6. Kuznetsova I.V. Rol' i znacheniye ozdorovitel'noy aerobiki v fizkul'turnom obrazovanii studentov vuzov // Sbornik materialov Mezhdunarodnoy nauchno-prakticheskoy konferentsii. Shuya: SHGPU. 2002. S. 85-86.

7. Osychenko M.V. Fitnes kak glavnyy komponent formirovaniya zdorovogo obraza zhizni studencheskoy molodezhi // Vestnik APK Stavropol'ya. 2012. №4(8) S. 12-14.

Поступила в редакцию 01.06.2021 г. Принята к публикации 01.07.2021 г.

Для циитирования:

Кузнецова И.В. Реализация вариативного компонента дисциплины «физическая культура» на основе цифровых фитнес-технологий // Вестник Гуманитарного института. 2021. №2. С. 55-59.

URL: https://isuct-bhi.ru/sites/default/files/issue/2021/1/bhi-2021-1-055.pdf 